Augusto Sérgio Pinto Guimarães, engenheiro civil de obras hidráulicas de saneamento;

consultor residente do Projeto Desenvolvimento

e Implementação de Projeto de Investimentos em

Saneamentos de Baixo Custo, financiado pelo

Programa das Naç̃es Unidas para o

Desenvolvimento - PNDU -, executado pelo

Banco Mundial e tendo o Conselho Nacional de

Desenvolvimento Urbano - CNDU - como

agência implementadora pelo governo brasileiro.

Membro do grupo assessor de saneamento, coordenador pelo CNPq, professor assistente da

Escola de Engenharia da UFRJ.

\title{
Alguns aspectos de dependência tecnológica e de alternativas para saneamento em meio urbano
}

Alguns aspectos de dependência tecnológica e de alternativas para saneamento em meio urbano

Os conceitos básicos ultilizados em esgotamento sanitário no Brasil são, de longe, o maior problema em saneamento, conseqüência de vícios e incorreções que têm colocado os sistemas de esgotos sob problemas de inviabilidade, em contraste, por exemplo, com o que ocorre com abastecimento de água.

\section{Dependência}

Pode-se, inicialmente, caracterizar algumas das formas mais comuns, de dependência tecnológica no setor, apresentadas no país (figura 1). A primeira delas é a utilização de concepç̃es de saneamento ${ }^{1}$ correntes em áreas ricas de países ricos.

O que se tem observado são investimentos que consideram apenas uma opção dentre as inúmeras disponíveis e sanitariamente adequadas, capazes de contribuir para solucionar o quadro desfavorável em que ainda se encontram as comunidades pobres do nosso país: é o sistema convencional de afastamento de esgotos ${ }^{2}$, através de redes, que encaminham os efluentes para as estações de tratamento de esgotos (ETEs), onde serão posteriormente condicionados.
Figura 1

Formas de dependência tecnológica em saneamento

1. Categoria

UTILIZACÃ̃O DE CONCEPÇÕES

DE SANEAMENTO CORRENTES

EM AREAS RICAS DE PAISES RICOS

\section{Categoria}

INVERSÃO DE PRIORIDADES

NOS EQUACIONAMENTO E RESOLUÇÃO

DOS PROBLEMAS DE AFASTAMENTO, CONDICIONAMENTO E DESTINAC̣ÃO FINAL DOS ESGOTOS.

\section{Categoria}

UTILIZAC̣ÃO DE TECNOLOGIAS NÃO CONVENCIONAIS OU BRANDAS, MAS NÃO ADEQUADAS AO ATUAL NIVEL DE ORGANIZAÇÃO E HABITOS O MEIO TÉĆNICO E DAS COMUNIDADES INDA CARENTES.

O sistema, praticamente o único empregado pelas companhias de saneamento, caracteriza-se por admitir critérios que o tem levado à inviabilidade fi- 
nanceira. O principal deles refere-se à norma técnịca de projeto vigente 3 que, implicitamente, admite serem as redes instaladas sempre em zonas de tráfego intenso, com o seu lançamento se dando a profundidades mínimas exageradas, evidenciando-se daí o desperdício de custos. Pesquisa corrente, financiada pelo Departamento de Pesquisas Aplicadas do BNH (DEPEA) ${ }^{4}$ e elaborada pela Fundação Estadual de Engenharia de Meio Ambiente/Estado do Rio de Janeiro (FEEMA), mostra que em áreas de características físicas críticas em relação ao sistema convencional - como acontece na maior parte das grandes cidades brasileiras ainda com problemas de esgotamento sanitário - os custos de escavação da rede e das obras relacionadas (caso do esgotamento de valas de escoramento, do transporte do material escavado e do reaterro de valas) são responsáveis por $80 \%$ do valor da obra. Ou seja: apenas $20 \%$ do custo de lançar uma rede corresponde à compra e ao assentamento da tubulação. Dessa maneira, é fácil inferir que o principal esforço na busca de redução de custos, quando o sistema escoIhido é o de redes e demais unidades complementares, se deve dar na simplificação dos critérios atuais, que impedem o lançamento de canalizações a profundidades rasas, mesmo que as características do projeto favoreçam essa possibilidade.

Infelizmente, a tecnologia convencional de redes de esgotos adotada no Brasil praticamente vem seguindo as mesmas concepções originalmente empregadas nos países ricos. ${ }^{5}$ Essas concepções são aplicadas em áreas ricas desses países, onde o sistema convencional se viabiliza quase que aprioristicamente, desde que não existam problemas de densidade habitacional rarefeita.

Por outro lado, o quadro encontrado pelas companhias de saneamento, no Brasil, em relação à maioria absoluta das áreas ainda não atendidas, faz demandar por sistemas de baixo custo que sejam adequados do ponto de vista sanitário, e de proteção do meio ambiente, simplificados do ponto de vista da sua construção, satisfatórios - tanto quanto possível - em termos de conforto oferecido ao usuário, viáveis do ponto de vista financeiro e, principalmente, aceitos pelos usuários.

O tradicionalismo, resultante da dependência, vem causando grandes males ao setor de saneamento no Brasil. Embora algumas (poucas) companhias de saneamento brasileiras estejam envidando esforços para propor soluções mais consonantes com as características das enormes áreas (na sua maioria, pobres) ainda por atender, a verdade é que o único sistema ainda oficialmente considerado em larga escala é o convencional. E essa opção majoritária pelo sistema convencional mostra-se ainda mais conservadora do que a concepção de saneamento vi- gente em países ricos de economia pautada em princípios semelhantes aos brasileiros. Para exemplificar, menos importante que as 18 milhões de residências nos Estados Unidos ( $25 \%$ do total) que possuem sistemas de disposição local de esgotos ${ }^{6}$ é o fato de que a quantidade desses sistemas vem crescendo à taxa de 500 mil novas unidades ao ano, ou seja, à mesma taxa de crescimento da população americana.

Voltando ao saneamento no Brasil, ainda haverá que citar o fato de que a escolha apriorística, feita na maioria absoluta das vezes pelo sistema convencional, torna também o meio técnico assaz despreparado para implementar outras soluções. É o caso dos conjuntos habitacionais tipo $\mathrm{COHAB}$, para os quais já existe quase que aceita a solução fossa séptica-sumidouro, independentemente de estudos técnicos, simplesmente porque se pensa ser uma alternativa de baixo custo ao sistema convencional.

Tecnicamente, a escolha muitas vezes tem fracassado porque pouco se estudam as condições de adequação do solo à infiltração do efluente dos sumidouros, não sendo incomum a instalação de fossas-sumidouros em terrenos impermeáveis, ou mesmo em áreas onde o lençol freático seja muito raso. Operacionalmente, o sistema fica tão-só aos cuidados do morador, que jamais é ao menos informado sobre a periodicidade com que se deve providenciar a retirada do lodo acumulado das fossas, já que dessa tarefa nunca haverá órgão do poder público que se ocupe. E do ponto de vista financeiro, a situação fica falaciosamente resolvida, pois quando não se consideram os custos de operação do sistema, esses custos são transferidos à conta do morador; e se este não participa, o resultado do abandono do sistema traduz-se pela degradação sanitária e ambiental da área.

O segundo aspecto a ser abordado será a inversão das prioridades no equacionamento e resolução dos problemas de afastamento e destinação final dos esgotos produzidos.

Historicamente, a engenharia sanitária brasileira tem investido parte ponderável dos (escassos) recursos disponíveis na construção de unidades de condicionamento de esgotos, as estações de tratamento de esgotos (ETEs). Essas unidades se constituem, na prática, de equipamentos importados ou fabricados sob licença de empresas internacionais. Pelo lado político dos investimentos, a execução das ETEs traz muitos 'benefícios', pois são obras visíveis. De outra forma, as redes de esgotos, se for essa a opção adotada para afastamento dos despejos, são obras subterrâneas, de cuja existência a população beneficiária rapidamente se esquece desde que estejam funcionando bem.

Em comparação com as unidades de coleta e 
transporte, as ETEs são mais fáceis de construir, sobretudo porque ocupam área bem delimitada e normalmente já pertencente ao poder público, não interferem nas redes de outros serviços urbanos, e interferem muito pouco na vida da cidade. A instalação de redes, por sua vez, quase sempre obriga o remanejamento de serviços urbanos existentes, exige conservação periódica e, enfim, causa transtornos à circulação de pessoas e veículos. Instalações individualizadas - que também podem excluir a construção de ETEs - fazem parte do conjunto da própria habitação, não podendo em conseqüência ser 'inauguradas' especialmente. Em contrapartida, podem provocar problemas aos usuários durante os serviços de manutenção, mesmo se executados por órgãos públicos.

Para agravar ainda mais o problema, o projeto e a operação das ETEs permitem um sem-numéro de alternativas, o que tem tornado aquelas unidades objeto de teses acadêmicas e trabalhos técnicos, valorizando, desse modo, o engenheiro de saneamento que se dedica ao tratamento de esgotos. Esses fatores, somados, vêm desmerecendo o técnico que se dedica aos problemas de coleta e transporte, tornando-o, mesmo, um profissional de segunda categoria no enteder daqueles que estudam e trabalham apenas com tratamento de esgotos.

\section{Dentro do quadro apresentado, piores ainda} são os problemas referentes às instalações domiciliares. A engenharia sanitária brasileira praticamente se recusa a conferir-Ihe qualquer importância e, nesse sentido, a tecnologia utilizada em aparelhos sanitários está concebida muito mais em termos de estética do que em relação à economia de água! $E$ como a estética-padrão é a que corresponde a modelos e normas em uso nos países desenvolvidos, o uso dos aparelhos sanitários convencionais encarece os sistemas muito além do que se fossem projetados com base no não-desperdício de água e na viabilidade econômica de todo o sistema de saneamento. Ainda a respeito das instalações prediais, nota-se que a execução das obras e serviços de saneamento nas residências é reservada a profissional especialmente dedicado à construção civil, sem formação em saúde pública. Esse profissional também não recebe qualquer apoio técnico em relação ao fato de que se executam instalações que são extremamente vinculadas à saúde dos moradores e, em visão ampliada, à saúde da comunidade.

A realidade atual brasileira em saneamento vem definindo uma situação de hierarquização dos técnicos especializados segundo os respectivos ramos de atividades, qual seja: primeira categoria os que se dedicam a tratamento, condicionamento e destinação final de esgotos; segunda categoria - os que se dedicam à coleta e transporte dos esgotos; e, finalmente, terceira categoria - aqueles que se dedicam às instalações domiciliares ou aos sistemas de disposição local dos esgotos.

Essa situação global predomina, em função de uma visão importada e mal digerida no Brasil. E por quê? Porque em relação a sistemas convencionais, os países desenvolvidos já resolveram os problemas referentes a instalações domiciliares, coleta e transporte dos esgotos, de tal maneira que dispõem de recursos para investir em tratamento e destinação final dos esgotos. Nossa visão e mobilização errôneas nos fazem pretensamente saltar obstáculos, esquecendo-se de que os aspectos de saúde mais importantes estão exatamente na ordem inversa àquela com que a engenharia sanitária brasileira vem privilegiando a execução de obras e serviços em esgotamento sanitário.

A situação piora ainda porque, mesmo entre os países ricos, começa a sedimentar-se no setor do saneamento uma consciência contra o desperdício, já colocada em prática a partir das instalações sanitárias. Nos países nórdicos é prática então estabelecida a produção de vasos sanitários de descarga reduzida (VDRs), projetados de forma a consumir apenas seis litros de água (tratada!), em vez dos doze/vinte litros gastos pelas peças convencionais as únicas fabricadas no Brasil. Os recursos, naqueles países, continuam a ser investidos atualmente no sentido de otimizar-se a tecnologia de modo a conseguir-se um VDR capaz de efetuar com apenas três litros de água a operação de limpeza requerida. Números frios sobre consumo de água em uma unidade tão desinteressante como um vaso sanitário certamente não devem realçar a importância do problema do desperdício de água. Talvez ao considerarmos economias alcançáveis do ponto de vista de um conjunto de beneficiários, o apelo seja outro. Nesse sentido, é válido afirmar-se que economia de monta poderia ser obtida nos custos residenciais dos sistemas de água e esgoto, desde que a redução do consumo mensal de água - e conseqüentemente na produção de esgoto - seja da ordem de cinco mil litros, apenas com utilização dos VDRs. Se, por um lado, as economias poderão até mesmo justificar, ao mesmo em áreas pobres, a substituição dos vasos sanitários convencionais por VDRs lestudos preliminares assim o estão demonstrando), por outro, já evidenciam a necessidade de o Brasil investir recursos em seu desenvolvimento visando ao emprego em larga escala. Do contrário, seria indubitável afirmar que, em futoro não remoto, o Brasil estaria discutindo aspectos de dependência tecnológica em relação à redução do desperdício de água em sistemas de saneamento. 
Utilização de tecnologias chamadas não-convencionais, mas inadequadas ao nível de organização social e aos hábitos das comunidades ainda carentes

Grande parte dessas tecnologias são, do ponto de vista ambiental, menos predatórias que as convencionais, em termos de uso de recursos naturais ou energéticos, embora às vezes exijam custos de investimentos mais elevados.

Em nosso país, são ainda muito irrelevantes os exemplos de utilização doméstica de tecnologias alternativas, em atividades de valor econômico mensurável, nas obras e nos serviços de saneamento. Dessa forma, há de se ter bastante cuidado com o transporte in totum de alternativas tecnológicas nãoconvencionais, úteis e aplicadas em outros países, mas que podem estar em defasagem com o estado de organização social e com a cultura de várias das comunidades brasileiras.

Será interessante apresentar um exemplo de tecnologia alternativa corrente em país não desenvolvido - um fato ocorrido no Vietnã. Essa tecnologia já foi objeto de inúmeras discussões e tentou-se até a sua utilização no Brasil, desconsiderando-se, entretanto, os aspectos sociais envolvidos; a conseqüência foi o fracasso das iniciativas. O exemplo refere-se à chamada 'privada vietnamita' (figura 2). Essa privada é projetada de tal maneira que os moradores dela apenas se utilizam para a defecação, sendo a urina encaminhada através de uma pequena canaleta para um jarro e, deste, disposta em buracos no solo. ${ }^{7}$ De um lado, a deposição apenas de fezes faz com que a taxa de carbono-nitrogênio possa aproximar-se e muito do valor ótimo de $30: 1$, facilitando assim o processo da decomposicão das fe-

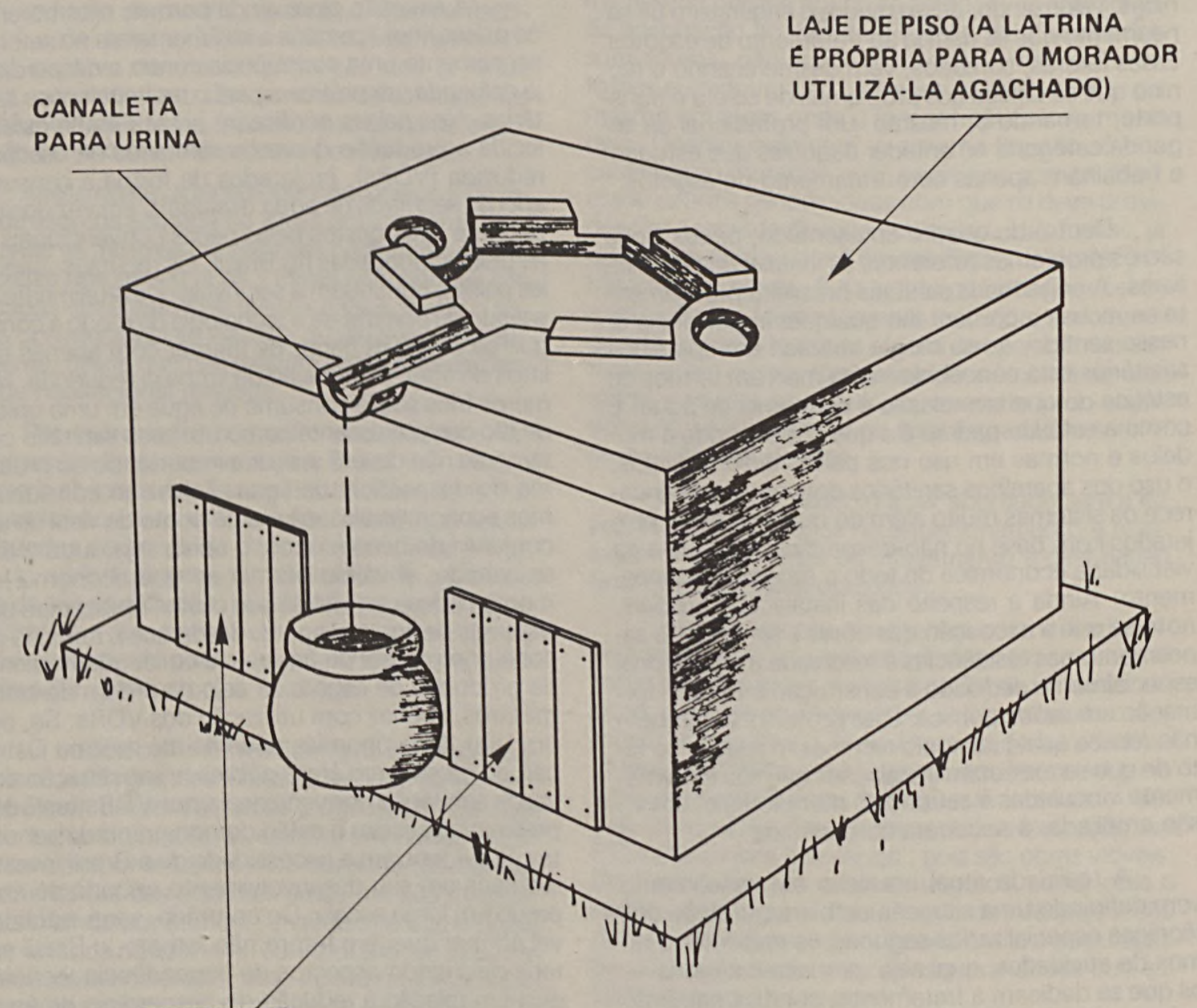


Żes; do outro, a separação física de fezes e urina está em desacordo com os hábitos da população carente brasileira, resultando que as tentativas feitas no Brasil para a utilização da 'privada vietnamita' terminaram em insucesso.

\section{Planejamento de sistemas em áreas urbanas}

Uma ação que vise à aplicacão de uma tecnologia apropriada às áreas (normalmente pobres) ainda carentes em saneamento irá passar, necessariamente, pela redefinição do planejamento dos sistemas. Em outras palavras, algumas das propostas referentes ao planejamento de sistemas de saneamento precedem a revisão da tecnologia. Eé sob essa ordem que serão desenvolvidas as idéias a propósito abaixo apresentadas.

Por que colocar em discussão o planejamento dos sistemas de saneamento? Esta é, sem dúvida, a primeira pergunta que faria aquele que desconhece a problemática do setor. A melhor maneira de respondê-la seria com a superposição, sobre um mapa das áreas urbanas brasileiras, da distribuicão da população segundo dois indicadores: atendimento com serviços públicos de saneamento e renda segundo diversas classes. Do resultado da superposição, seria imediato declarar que as áreas pobres ${ }^{8}$ estão marginalizadas dos sistemas públicos de saneamento. Como conseqüência, então, seria correto, como primeiro passo, buscar propostas de so- lução que visassem, de forma ordenada, à ampliação do atendimento a 'toda' a população moradora da área em questão. E essa é a única maneira de methorar o padrão sanitário da área em estudo. Não basta, como ainda agem alguns poucos, sofisticar o máximo o nível de serviços propiciados àqueles que podem pagar muito e simplesmente não ofertar serviço algum àqueles que pouco ou nada podem pagar. Os problemas de saúde pública, minimizados ao limite ou aumentados respectivamente pela presença ou falta dos serviços de saneamento, atingem toda a mancha urbana de uma área em estudo e essa mancha, em casos de áreas metropolitanas, pode alcançar alguns milhares de quilômetros quadrados.

Como segundo passo, admitir-se-á que a área em estudo possa ser dividida em subáreas, possibilitando, dessa forma, que grupos populacionais de características diferenciadas recebam atendimento em niveis de serviços diferenciados - ressalvado o fato de que o padrão sanitário conveniente estará assegurado em qualquer das alternativas consideradas adequadas.

Quando for o caso de optar-se por sistemas simplificados de esgotamento sanitário, é decisivo que os projetistas considerem as áreas que serão beneficiadas sob grau de precisão muito elevado. Isto significa que não basta apenas dispor de plantas topográficas nas escalas adequadas. É necessário também, e principalmente, conhecer in situ todas as peculiaridades da área considerada e que devam estar em foco no projeto visando à redução dos custos.

FIG. 3

AV. DESEMBARGADOR NESTOR

RODRIGUES PERLINGEIRO

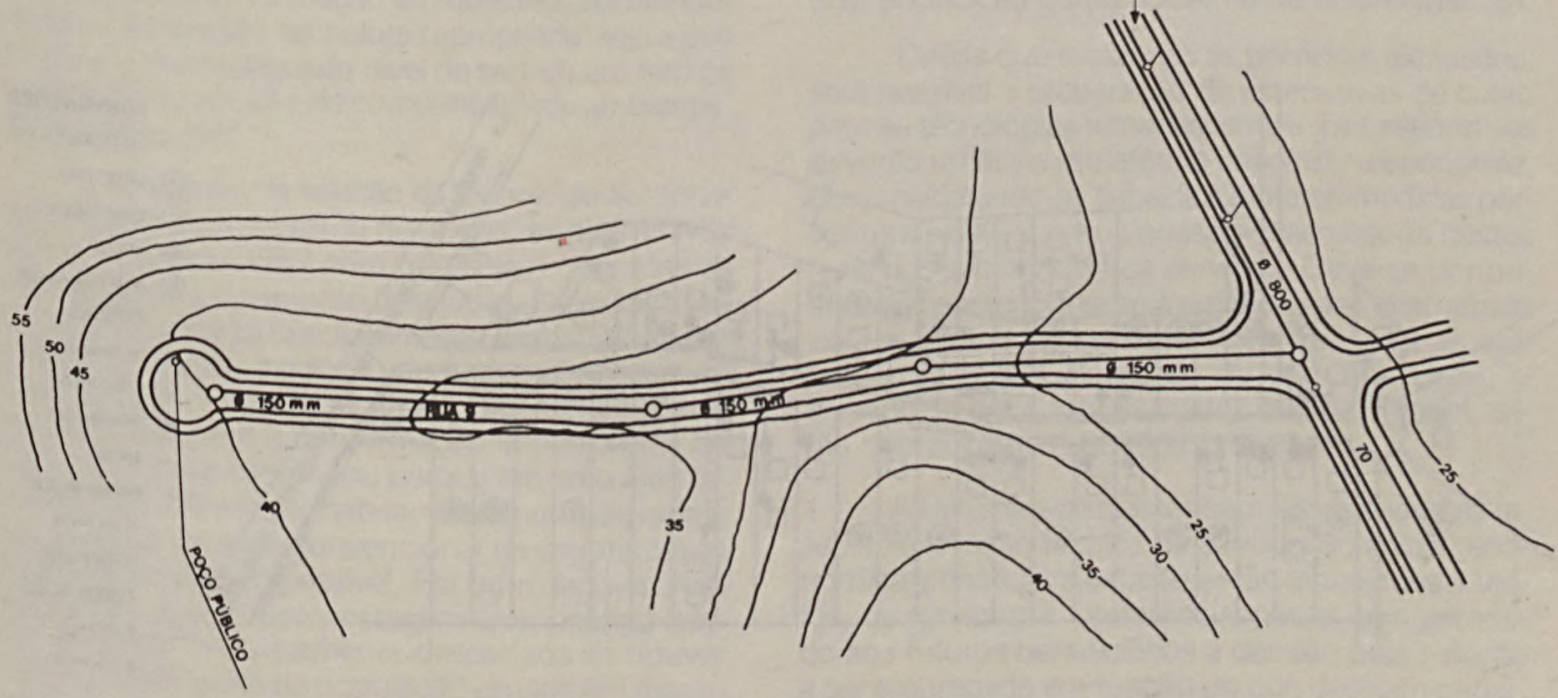


A esta maneira de se trabalhar pode-se dar o nome de projeto em escala $1: 1.9$

Com o intuito de tornar possivel uma fixação mais consistente do conceito de escala 1:1, julgamos pertinente comunicar uma de nossas experiências de campo em saneamento de baixo custo, a que foi realizada em Santa Bárbara, bairro da periferia situado em Niterói10, e que passamos a descrever.

A figura 3 mostra o projeto convencional que havia sido executado para a rua 9 do bairro de Santa Bárbara, evidenciando-se o fato de que ao projetista somente lhe bastava dispor de plantas topográficas em escala adequada, desde que para uma área limitada como aquela praticamente não seria necessário o conhecimento da realidade física local.

Da completa inviabilidade financeira de realizar-se a obra projetada convencionalmente, passou-se ao trabalho baseado nos recuros locais disponíveis, com vistas à redução dos custos, como forma de tornar realizáveis as obras de saneamento. Desvios de um pequeno afloramento rochoso, assim como o poço público existente, utilização de ligações domiciliares existentes e aproveitáveis e eliminação das inservíveis, minimização das escavações pelo fato de as redes (paralelas) terem sido lançadas nas calçadas (devidamente protegidas por encamisamento de concreto quando atravessavam portas de garagem) - foram estas algumas das características do projeto (figura 4) transformado em obra, resultante de contínuas negociações realizadas com os moradores e com sua associação representante.
Procurando consolidar a viabilização dos sistemas de saneamento de baixo custo, surge também como elemento de importância o trinômio IME - informação, motivação e educação. À população usuária, seja direta ou indiretamente através das diversas formas de representação da sociedade, deverá ser possível participar das decisões, em todas as fases, sobre as atividades relacionadas com o projeto de saneamento a ser executado, desde a concepção até às etapas de operação (nesta incluindo a efetivação dos serviços) e manutenção. Esta atitude certamente aumentará substancialmente as probabilidades de sucesso do empreendimento.

Observe-se, ainda, que as ações relacionadas ao IME, embora compreendam o que tradicionalmente se denomina de educação sanitária, possuem um escopo mais amplo. Com efeito, discussões relativas às características das alternativas possíveis, estímulo a ações de participação direta dos usuários - incluindo o pagamento pelos serviços - , além do incentivo à adoção de práticas sanitárias mais corretas, quando for o caso, fazem parte de uma concepção mais ampla e mais moderna do que sejam as atividades de apoio de comunicação aos projetos de saneamento.

\section{Estruturação dos projetos de saneamento}

A seqüência proposta para estruturação dos projetos de saneamento (figura 5) ${ }^{11}$ procura mostrar ao projetista a necessidade de se contar com uma equipe multiprofissional. Com essa estruturação, es-

\section{FIG. 4}

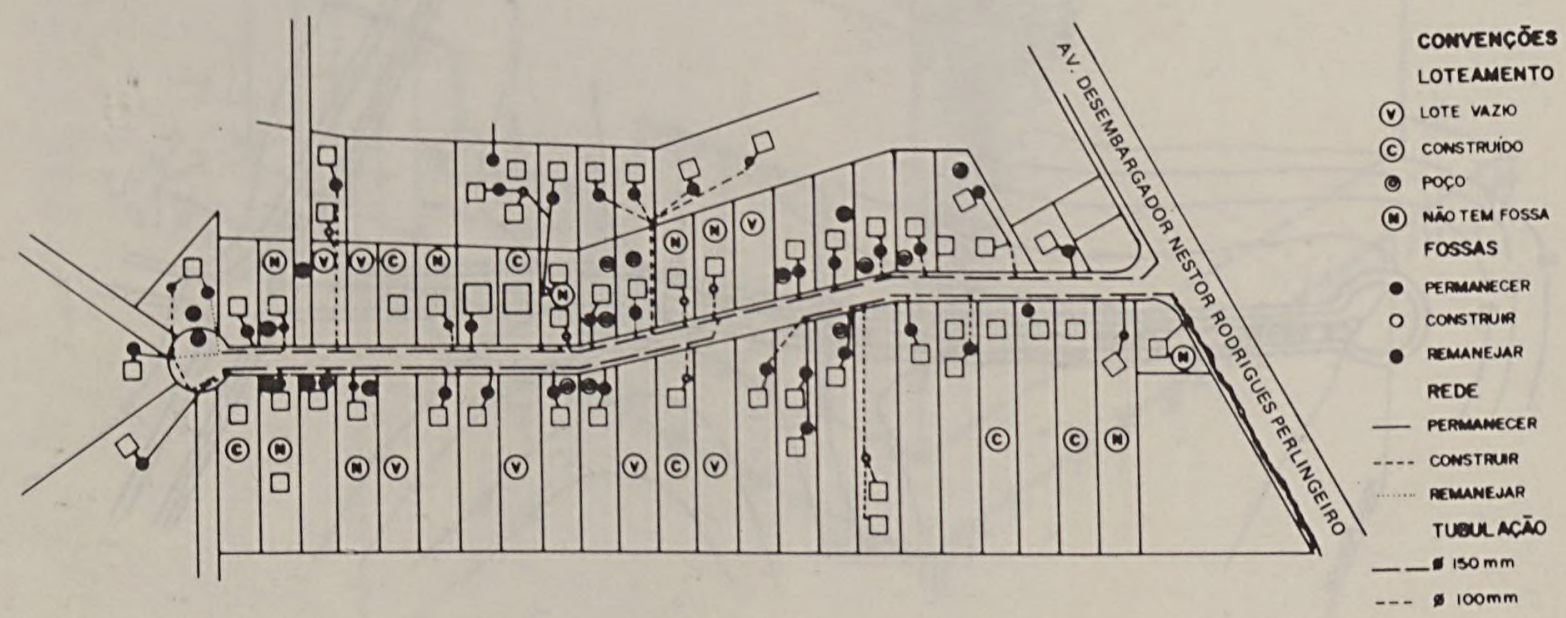




\section{Estrutura recomendada para planejamento de programas de saneamento}

\begin{tabular}{|c|c|c|c|c|}
\hline $\begin{array}{l}\text { ENGENHEIRO } \\
\text { SANITARISTA E } \\
\text { ESPECIALISTA } \\
\text { EM SAUUDE PÜBLICA }\end{array}$ & ECONOMISTA & $\begin{array}{l}\text { TEECNICO EM COMU- } \\
\text { NICACCÃO SOCIAL }\end{array}$ & COMUNIDADE & \\
\hline $\begin{array}{l}\text { Verifica con- } \\
\text { diçōes fisicas } \\
\text { e ambientais; esta- } \\
\text { belece os beneficios } \\
\text { sanitários a serem } \\
\text { atingidos. }\end{array}$ & $\begin{array}{l}\text { Coleta infor- } \\
\text { mação de inte- } \\
\text { resse macroeco- } \\
\text { nômico. }\end{array}$ & $\begin{array}{l}\text { Apropria, da comuni- } \\
\text { dade, informaçōes so- } \\
\text { bre práticas existentes } \\
\text { e preferências. }\end{array}$ & $\begin{array}{l}\text { Transmite práticas } \\
\text { e preferências. }\end{array}$ & ESTÁGIO 1 \\
\hline \multirow[t]{2}{*}{$\begin{array}{l}\text { Identifica e avalia } \\
\text { custos de alter- } \\
\text { nativas técnica e } \\
\text { sanitariamente viáveis. }\end{array}$} & $\begin{array}{l}\text { Identifica } \\
\text { restriçōes } \\
\text { econômicas. }\end{array}$ & $\begin{array}{l}\text { Apresenta alternativas } \\
\text { sócio e institucional- } \\
\text { mente viáveis. }\end{array}$ & & ESTAGIO 2 \\
\hline & $\begin{array}{l}\text { ernativas } \\
\text { veis. }\end{array}$ & $\begin{array}{l}\text { Identifica as contri- } \\
\text { buiç̋̃es possiveis de } \\
\text { serem oferecidas pela } \\
\text { comunidade e capaci- } \\
\text { dade de pagamento aos } \\
\text { sistemas. }\end{array}$ & - Orienta. & ESTAGIO 3 \\
\hline \multirow[t]{3}{*}{$\begin{array}{l}\text { Prepara projetos exe- } \\
\text { cutivos e estimativas } \\
\text { de custos unitários } \\
\text { para as alternativas } \\
\text { viáveis. }\end{array}$} & & $\begin{array}{l}\text { Procura estabelecer } \\
\text { acordos com relação } \\
\text { à participação da co- } \\
\text { munidade. }\end{array}$ & -Orienta. & ESTAGIO 4 \\
\hline & $\begin{array}{l}\text { Prepara custos } \\
\text { financeiros dos } \\
\text { sistemas viáveis. }\end{array}$ & & & ESTAGIO 5 \\
\hline & & & $\begin{array}{l}\text { Seleciona a alter- } \\
\text { nativa mais conve- } \\
\text { niente. }\end{array}$ & ESTÁGIO 6 \\
\hline
\end{tabular}

pera-se que a tecnologia escolhida seja realmente a mais apropriada à situação em questão, admitindose que a expressão 'tecnologia apropriada' seja a que traduza o mais adequado nível de serviço em termos de 'aceitação social e de compatibilidade ambiental, ao menor custo'.

O processo de seleção da tecnologia apropriada inicia-se com o exame de 'todas' as alternativas técnicas disponíveis ${ }^{12}$ para que sejam operadas as melhorias de saneamento desejadas. Na prática, algumas delas serão imediatamente descartadas, por exemplo, porque a adoção de fossas sépticas e de unidades de infiltração local dos efluentes revela-se incompatível com a conformação impermeável do solo da área em estudo; ou porque em uma área favelada com densidade habitacional muito elevada o lançamento da rede convencional de esgotamento sanitário torna-se impossível. Por outro lado, a alternativa da fossa de compostagem (composting latrine) pode ser imediatamente descartada se houver restrições por parte da população usuária em manusear ou, até mesmo, ver os excretas da forma concentrada; pode também ocorrer o mesmo com a pri- vada seca, em áreas urbanas, por ser considerada pela população como socialmente discriminatória.

Desde que realizadas as primeiras exclusões, será possível a preparação de estimativas de custo para as tecnologias remanescentes. Tais estimativas deverão refletir o seu efetivo impacto na economia, desconsiderando-se subsídios e outras medidas porventura existentes que possam mascarar os custos reais dos sistemas e dos serviços. Deve-se por outro lado, posteriormente à definição das alternativas viáveis economicamente, também proceder às avaliações de custo, do ponto de vista financeiro, aí levando-se em conta os custos que 'realmente' serão cobrados aos usuários.

As alternativas que tenham ultrapassado as fases de avaliação técnica de adequação social, econômica e financeira estarão então vinculadas a tarifas, de modo que, preferencialmente, seja permitido aos futuros beneficiários a decisão pela solução a ser empregada em função do que desejam pagar. Essa última etapa é, sem dúvida, a parte mais crítica de todo o processo, desde que de antemão já se 
sabe das dificuldades advindas da pretensão de apurar-se o interesse da comunidade. Ainda assim, esse é o processo mais importante para que se possa identificar a 'solução ótima', do ponto de vista do beneficiário, sendo conveniente que se comece a estudar maneiras de tornar efetivo o relacionamento entre a sociedade e as autoridades do setor do saneamento.

Talvez, dentro das possibilidades atuais, seja factível o encontro de solução mais próxima da ótima. Procura-se, por exemplo, de forma indireta, entre as opções anteriormente 'filtradas', as que já forem mais utilizadas pela comunidade a ser beneficiada com o novo sistema de saneamento, mesmo que se tratem de tecnologias passiveis de receber meIhorias.

A seqüência proposta evidencia, de forma estruturada, o inter-relacionamento profissional que deve pautar o projeto de saneamento. Desde que é operacionalmente muito complicado o processo interativo, sugere-se que, como foi apresentado, se aplique à sistemática seqüencial convergente para que se chegue à decisão pela solução mais apropriada do projeto em estudo.

O estágio 1 sugere que cada especialista organize o conjunto de informações necessárias ao teste de viabilidade afeto à sua capacidade profissional - as informações de caráter físico e social deverão ser obtidas preferencialmente no campo, ao passo que ao economista competiria obter (principalmente do poder público) as informações necessárias aos seus estudos de viabilidade.

O estágio 2 compreende, justamente, a realização dos diversos estudos de viabilidade necessários e/ou a definição de tecnologias passíveis de serem utilizadas, segundo as diversas alternativas em questão.

O estágio 3 considera a seleção, realizada pelo economista, das tecnologias que tenham sido bem sucedidas nos testes de viabilidade, seleção essa que será fundamentalmente subsidiada pelos estudos capazes de definir o nível de contribuição da comunidade, bem como sua capacidade de pagamento.

O estágio 4 compreende a preparação de projetos básicos, por parte do engenheiro de saneamento, em paralelo a um trabalho de discussão com a comunidade - encaminhado pelo técnico de comunicação - que, em última análise, deveria ser ouvida para aprovar o detalhamento dos projetos.

O estágio 5 considera a preparação, pelo economista, dos custos financeiros das alternativas julgadas viáveis.

O estágio 6, idealmente, deve passar pela decisão da comunidade sobre a solução a ser adota- da, desde que, obviamente, é a população beneficiária que pagará pelo sistema novo a ser implementado, ou pelas melhorias que serão introduzidas no sistema já existente.

\section{Alternativas}

A tendência tecnológica brasileira em saneamento, e especialmente em esgotamento sanitário, mostra que ainda não estão conceituadas de forma adequada as principais diretrizes úteis para implantar-se uma tecnologia alternativa, técnica e sanitariamente apropriada, aceita pela população, viável do ponto de vista financeiro, e não-predatória em termos de utilização de recursos energéticos e naturais.

Por outro lado, desde que seja possível o planejamento e a estruturação conveniente de projetos que visam à expansão do saneamento às áreas (normalmente pobres) ainda carentes do serviço, poderá ser realizada, de maneira imediata, a colocação em prática de uma alternativa tecnológica adequada. Deve-se frisar que, para se queimar etapas em função das condições muito deficientes do setor, o processo de implantação da tecnologia alternativa deverá alcançar praticamente, ao mesmo tempo, tanto os meios técnicos de projeto, como o setor industrial.

O principal condicionante do conceito de tecnologia alternativa refere-se à economia de utilização de energia e de recursos naturais - no caso, principalmente à água. Nesse sentido, sempre é bom lembrar a 'Segunda lei da termodinâmica', que declara "a não ocorrência de qualquer processo de transformação de energia sem que não haja uma concomitante degradação de energia de uma forma concentrada para uma forma mais dispersa". Isso significa que a volta ao ponto da mesma energia potencial gasta-se outro quantum de energia e, se o objetivo é retornar ao nível energético inicial ('controlando a poluição'), o caminho ótimo 'sempre' passa pela minimização do consumo de energia entre a ida ('poluição') e o retorno ('controle')

Traduzindo isso para os aspectos de saneamento e, à sua falta, os de poluição e contaminação, verifica-se que a tecnologia convencionalmente adotada no Brasil não leva em conta o critério importante da economia de energia, ou seja: gasta-se energia demasiada para produzir obras e serviços de saneamento resultando, em conseqüência, dispersão demasiada da poluição - vai-se gastar, igualmente, energia também demasiada para o controle da poluição.

No caso brasileiro significa que, como país carente de Terceiro Mundo, a diretriz deverá ser diferente daquela dos países ricos, que poluíram o mais 
que puderam seus sistemas naturais e agora gastam milhões para despoluí-los. O exemplo da recuperação do Rio Tâmisa não é, pelo menos do ponto de vista conceitual, a melhor alternativa brasileira. A alternativa brasileira é, primeiro, executar o sistema de saneamento para, com isso, minimizar problemas posteriores de poluição. Em outras palavras, podese afirmar que o objetivo da tecnologia brasileira de saneamento é utilizar, sempre que possivel, o inplant control, e não o end-of-pipe control.13

Dentro da perspectiva de economia de energia e água é que se devem considerar alternativas viáveis, do ponto de vista técnico, passíveis de empregá-las em saneamento. Nesse sentido, podese afirmar que os sistemas convencionais de esgotamento sanitário são dos piores sistemas de engenharia jamais projetados de ponto de vista de utilização de recursos naturais: 200 gramas de matéria fecal e $1000 \mathrm{ml}$ de urina, ambos produzidos por habitante e por dia, normalmente utilizam para sua veiculação 80 litros de água, também por habitante e por dia ${ }^{14}$, água essa tratada a custo elevado, mostrando a enorme agressão ambiental perpetrada por aquele sistema de engenharia.

É sobre esse desperdício que se deverá centrar, futuramente ou a curto prazo, grande parte das alternativas viáveis para saneamento. O que se pode então prever é o desenvolvimento de uma tecnologia própria, capaz de resolver o problema trivial de afastar fezes e urina, gastando o mínimo de água possivel, de modo a se produzir, no Brasil, aparelhos e equipamentos (por exemplo os VDRs conforme indicado) que executem corretamente suas funçõs dentro de um projeto de saneamento.

\section{Notas e Referências}

1. Meramente por simplificação, admitiu-se que a palavra 'saneamento' esteja sempre relacionada a sistemas para afastamento de esgotos.

2. Consideram-se como sistemas convencionais, estritamente para fins de compreensão deste texto, os que se apóiam no conjunto de Projetos de Normas editado pela Associacão Brasileira de Normas Técnicas - ABNT, de numeros 566, 567, 568, 569 e 570

3. Associação Brasileira de Normas Técnicas. Elaboração de projetos de redes de esgotos sanitários. Rio de Janeiro, 1975. 23p. (PNB-567);

4. Fundação Estadual de Engenharia do Meio Ambiente. Otimização de redes de esgotos sanitários. Rio de Janeiro, 1981, 3 v.

5. American Society of Civil Engineers \& Water Pollution Control Federation. Design and construction of sanitary and storm sewers. Washington, D.C.WPCF, 1976. 283p. (ASCE, Manual of engineering practice, 37; WPCF, Manual of practice, 9).
6. EUA. Environmental Protection Agency. Onsite wastewater treatment and disposal systems; design manual. Washington, D.C., U.S. Govt. Print-Off., 1980. 391p. (Technology Transfer, EPA-625/1-80-012).

7. WINBLAD, U. et alii. Sanitation withouth water. Stockhold, Swedish International Development Authority, 1980, 133p.

8. Entendendo-se, no texto, por 'áreas pobres' aquelas onde a renda familiar mensal média situa-se abaixo de três salários minimos regionais.

9. Terminologia utilizada na Companhia de Saneamento Básico do Estado de São Paulo - SABESP.

10. Fundação Estadual de Engenharia do Meio Ambiente - FEEMA. Ecodesenvolvimento em áreas urbanas do Rio de Janeiro. Rio de Janeiro, 1981, 6v.

11. The World Bank. A planner's guide, by John Kalbermatten et alii, Washington, D.C., 1980 - 194p. (Appropriate technology for water supply and sanitation, 11).

12. Admite-se, por definição, que somente estejam em questão alternativas que sejam aprovadas do ponto de vista sanitário

13. RAMALHO, R.S. Water pollution control engineering, Rio de Janeiro, COPPE/UFRJ, 1974 - 3v. ilust. (Publ. didática, 1/74).

14. MARA, David D. Sewage treatment in hot climates. Chichester, John Wiley, 1978, 168p

\section{Bibliografia}

1. GUIMARÃES, Augusto Sérgio P. Projetos demonstrativos em saneamento de baixo custo; - relatório especial. Rio de Janeiro, PNUD/Banco Mundial, 1981.34p. (Projeto Global $\mathrm{GLO} / 78 / 006)$

2. Relatório de inspeção a Natal, Rio Grande do Norte. Rio de Janeiro, PNUD/Banco Mundial, 1981 (Projeto Global GLO/78/006).

3. Dependência tecnológica e alternativas em saneamento; Recife, 1982. 17p.; (palestra realizada no Encontro Nacional da Construção - ENCO).

4. Revista Brasileira de Tecnologia; Alguns aspectos de dependência tecnológica e de alternativas em saneamento, 1983 $-8 p$.

5. READ, G. Demonstration projects in low-cost water supply and sanitation; memo to the project manager Mr. Richard Middleton. London, UNDP/World Bank, June 1981, 17p. (Global Project GLO/78/006);

6. London. UNDP/World Bank, January 1981. 29p. Global Project GLO/78/006)

7. KUHLTHAU, R.H. Appropriate technology for water supply and waste disposal in developing countries; country studies in appropriate sanitation alternatives, Washington, D.C. The World Bank, 1979, 176p. (P. U. report, res. 21).

8. IMHOFF, K. \& FAIR, G. M. Sewage treatment, 2ed. New York, John Wiley, 1956.

9. BRITO, Saturnino de. Saneamento de Recife. Rio de Janeiro Imprensa Nacional, 1943. 2t. (Obras completas de Saturnino de Brito, 8);

10. SWAFFIELD, J. Demonstration projects in low-cost water supply and sanitation; report on mission to Brasil. London, UNDP/World Bank; 1981. 33p. IGlobal Project GLO/78/006; TAG/BRA/09). 
